\title{
Hyaluronan fragments induce IFN $\beta$ via a novel TLR4-TRIF-TBK1-IRF3-dependent pathway
}

\author{
Katharine E Black', Samuel L Collins ${ }^{1}$, Robert S Hagan', Mark J Hamblin ${ }^{1}$, Yee Chan-Li', Robert W Hallowell' \\ Jonathan D Powell ${ }^{2}$ and Maureen R Horton ${ }^{1 *}$
}

\begin{abstract}
Background: The extracellular matrix plays a critical role in insuring tissue integrity and water homeostasis. However, breakdown products of the extracellular matrix have emerged as endogenous danger signals, designed to rapidly activate the immune system against a potential pathogen breach. Type I interferons play a critical role in the immune response against viral infections. In the lungs, hylauronan (HA) exists as a high molecular weight, biologically inert extracellular matrix component that is critical for maintaining lung function. When lung tissue is injured, HA is broken down into lower molecular weight fragments that alert the immune system to the breach in tissue integrity by activating innate immune responses. HA fragments are known to induce inflammatory gene expression via TLR-MyD88-dependent pathways.

Methods: Primary peritoneal macrophages from C57BL/6 wild type, TLR4 null, TLR3 null, MyD88 null, and TRIF null mice as well as alveolar and peritoneal macrophage cell lines were stimulated with HA fragments and cytokine production was assessed by rt-PCR and ELISA. Western blot analysis for IRF3 was preformed on cell lysates from macrophages stimulate with HA fragments

Results: We demonstrate for the first time that IFN $\beta$ is induced in murine macrophages by HA fragments. We also show that HA fragments induce IFN $\beta$ using a novel pathway independent of MyD88 but dependent on TLR4 via TRIF and IRF-3.

Conclusions: Overall our findings reveal a novel signaling pathway by which hyaluronan can modulate inflammation and demonstrate the ability of hyaluronan fragments to induce the expression of type I interferons in response to tissue injury even in the absence of viral infection. This is independent of the pathway of the TLR2-MyD88 used by these matrix fragments to induce inflammatory chemokines. Thus, LMW HA may be modifying the inflammatory milieu simultaneously via several pathways.
\end{abstract}

Keywords: Hyaluronan, Macrophage, Interferon, Matrix, Lung

\section{Background}

The type I interferons have been implicated in a wide variety of host defense responses [1]. Though there are many type I interferons in humans $(\alpha, \beta, \omega, \kappa, \varepsilon)$, IFN $\beta$ and IFN $\alpha$ are the best described [1]. Multiple cell types produce each interferon, making the original distinction between "leukocyte" IFN (alpha) and fibroblast IFN (beta) obsolete [1]. These type I interferons share a common receptor, the interferon- $\alpha / \beta$ receptor [1]. IFNs

\footnotetext{
* Correspondence: mhorton2@jhmi.edu

'Department of Medicine, John Hopkins University School of Medicine, Baltimore, USA

Full list of author information is available at the end of the article
}

induce antiviral cellular responses to diverse stimuli, including LPS, Shigella, Plasmodium, Schistomsoma, Mycoplasma, trypanosomes, as well as viruses such as RSV [2-4].

Although cells usually produce IFN $\alpha$ and $\beta$ in response to viral or other infections, the interferons play a role in the absence of infection as well $[5,6]$. IFN $\beta$ production by plasmacytoid dendritic cells and Th1 T cells has been implicated in inhibiting Th2 cell migration in inflamed lungs in a model of allergic asthma [5]. Furthermore, low level IFN production has been observed in the absence of infection both in vivo and in vitro [6]. It has been proposed that this low level IFN production is

\section{Ciomed Central}


necessary for cells to mount a rapid and effective response to infections by priming the cells for further, rapid IFN responses [6].

Hyaluronan (HA) is a glycosaminoglycan found throughout the extracellular matrix. It plays a variety of roles both in maintaining structure and in responding to injury [7-9]. HA is produced predominantly in fibroblasts by three isoforms of hyaluronan synthase, and is released from the plasma membrane into the extracellular space [7]. It is abundant in the synovial and vitreous fluids and makes up $80 \%$ of the glycosaminoglycan in the lung [7]. In a healthy lung, HA exists predominantly in a high molecular weight form (6 million daltons) that is important in maintaining distribution of plasma proteins. High molecular weight $\mathrm{HA}$ is immunosuppressive by a variety of mechanisms including enhancing suppressive $\mathrm{T}$ regulatory cells, and inhibiting macrophage phagocytosis $[7,10]$. However, fragments of HA produced both by breakdown of high molecular weight forms and by direct synthesis by hyaluronan synthases have profound biological activities that diverge from these pro-homeostatic effects $[8,9,11]$. In the setting of tissue destruction, low molecular weight fragments of hyaluronan (200,000 daltons) accumulate and act as an endogenous "danger signal", inducing a host of inflammatory mediators [12-15]. These fragments have been shown to act via TLR2-MyD88-IRAK-PKC or TLR4MyD88 binding to promote the production of inflammatory chemokines, such as MIP- $1 \alpha$, MIP $1 \beta, \mathrm{KC}$, RANTES, MCP-1, IP-1, IL-12, IL-8 and TNF $\alpha$ [12-15].

In light of the emerging importance of hyaluronan in regulating inflammation in response to tissue injury, we sought to determine its potential role in regulating the induction of type I interferons. In this report we demonstrate the ability of HA fragments to promote IFN $\alpha$ and $\beta$ expression in the absence of viral infection. Furthermore, our studies reveal a previously unappreciated MyD88-independent signaling pathway responsible for HA-induced inflammatory gene expression. Thus, LMW HA may be modifying the inflammatory milieu simultaneously via several pathways.

\section{Methods}

\section{Cells}

MH-S cells (a murine alveolar macrophage line) or RAW 264.7 cells (a murine leukemic monocyte/macrophage line derived from ascites) were used (ATCC) [16]. Cells were cultured in RPMI or DMEM media with 10\% fetal bovine serum. For experiments, cells were washed in phosphate-buffered saline and stimulated in RPMI 1640 media with $1 \%$ glutamine and penicillin/streptomycin. Thioglycollate-elicted peritoneal macrophages were lavaged from female C57BL/6, TLR2 null, TLR4 null, TRIF null, TLR3 null (The Jackson Laboratory), or
MyD88 null (Akira and Gollenbeck) mice 4 days after injection of $3 \mathrm{~mL}$ sterile thioglycollate (Sigma-Aldrich). Before use, cells were allowed to adhere overnight in RPMI 1640 supplemented with $10 \%$ heat inactivated low-LPS FBS and 1\% penicillin-streptomycin/glutamine. To exclude the effects of contaminating LPS on experimental conditions, cell stimulation was conducted in serum-free RPMI, and in the presence of polymixin B at $10 \mu \mathrm{g} / \mathrm{mL}$ (Sigma-Aldrich) unless LPS was used as a stimulant. All animal experiments were approved by the Johns Hopkins Committee on Animal Use and experiments were conducted in accordance with their guidelines and regulations.

\section{Chemicals and reagents}

Purified LMW HA fragments (free of protein and other glycosaminoglycans), with a peak molecular weight of 200,000 Da derived from human umbilical cords, were purchased from Calbiochem. Polymixin B was purchased from Sigma. Ultrapure LPS was purchased from InvivoGen. HMW HA was purchased from Genzyme. HA disaccharides and chondroitin sulfate $B$ were purchased from Sigma. BX795 was purchased from Axon, Medcom.

\section{RT-PCR}

Total RNA was collected in Trizol reagent (Invitrogen), stored at $-20^{\circ} \mathrm{C}$. RNA was extracted per manufacturer's protocol. Purity and RNA concentration was measured using a NanoDrop (ThermoScientific). cDNA was prepared using Superscript III (Invitrogen) according to manufacturer's protocol. Real Time PCR was done using an ABI 7900 cycler and commercially available composite probesets for interferon beta (ABI). Eukaryotic $18 \mathrm{~S}$ was used as internal control. Data were presented as fold induction over unstimulated samples; for knockout mice experiments, data are presented as fold induction over wild-type unstimulated samples.

\section{Luciferase}

The human IFN-beta promoter luciferase reporter plasmid PGL-3-IFN-beta-LUC41 was a kind gift of J. Hiscott (McGill University, Montreal, Canada). RAW 264.7 cells were transfected with 0.5 ug of plasmid per 3million cells using lipofectamine 2000 (Invitrogen); cells were transfected for 4 hours, then allowed to rest in complete media overnight and replated in 96 or 12 well plates. Cells were then rinsed in warmed PBS and stimulated in serum-free RPMI with polymixin B (Sigma). Luciferase activity was measured using Bright-Glo (Sigma) and a microplate reader.

\section{ELISAs}

Cell cultures were stimulated with HA for the allotted time; supernatants were collected and stored at $-80^{\circ} \mathrm{C}$. 
until the ELISAs were performed. ELISAs for interferon $\beta$ (PBL) were performed according to manufacturer's specifications.

\section{Western blot analysis}

10 ug of whole cell lysates were fractionated by SDSPAGE (10\%), transferred to nitrocellulose membrane, blocked with $5 \%$ milk, washed, and incubated with primary antibodies to IRF-3 (1:1000) or phospho-IRF3 S396 (1:1000) (Santa Cruz Biotechnology). Secondary antibodies were purchased from GE Healthcare and developed with a chemiluminescent system according to the manufacturer's instructions (Amersham).

\section{Statistics}

All statistical analysis was conducted using the Student's t-test. Statistically significant values were considered to be those where $\mathrm{p}<0.05$.

\section{Results}

Low molecular weight HA fragments induces IFN $\beta$ In light of the critical role of Type I IFN in regulating infectious and non-infectious immune responses we sought to determine if endogenous HA fragments could act as a danger signal by inducing IFN $\beta$ in macrophages. Both alveolar macrophage and peritoneal macrophage cell lines were stimulated with HA fragments in serumfree RPMI. Total RNA and protein were isolated, and analyzed with quantitative PCR or ELISA. HA fragments induced IFN $\beta$ mRNA and protein in a dose-dependent fashion, with peak protein expression after $500 \mathrm{ug} / \mathrm{ml}$ HA (Figure 1a,b). IFN $\beta$ mRNA demonstrated a peak increase at 3 hour and peak protein at $6 \mathrm{~h}$ (Figure 1c,d). Of note, this peak occurred before HA fragment induced production of other inflammatory cytokines such as TNF- $\alpha$, suggesting that the production of IFN $\beta$ is a primary effect of HA, not a downstream effect of TNF- $\alpha$

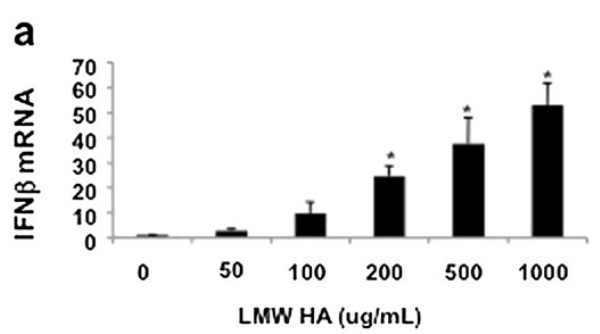

\section{b}
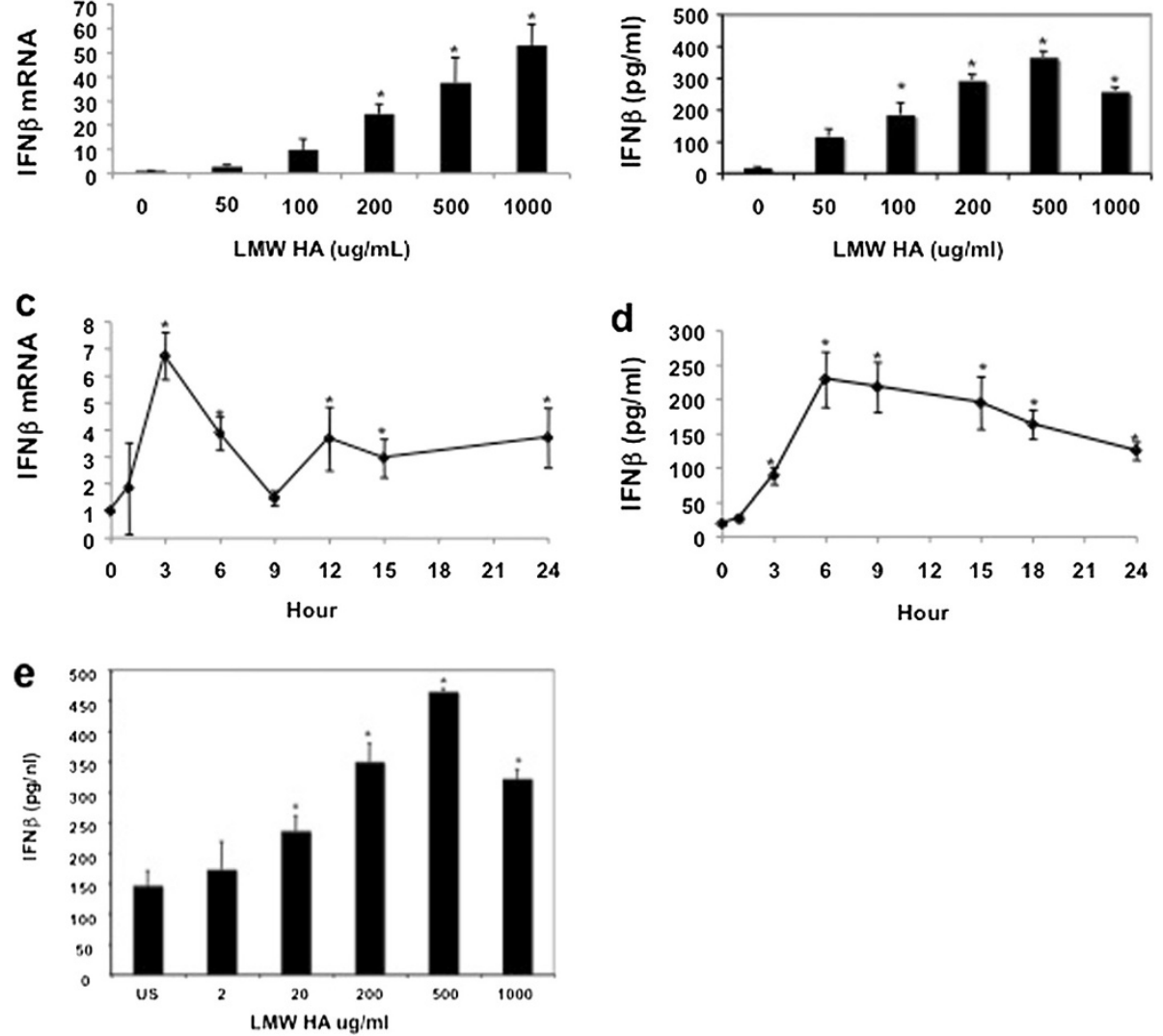

Figure 1 HA fragments induce IFN $\beta$ mRNA and protein. (a) MH-S alveolar macrophages were stimulated with low molecular weight (LMW) HA fragments, RNA extracted and Real-Time PCR performed for IFN $\beta$ normalized to $18 \mathrm{~s}$. HA fragments induce IFN $\beta$ mRNA in a dose dependent fashion with peak induction at $3 \mathrm{~h}$ with a dose $1000 \mathrm{\mu g} / \mathrm{ml}$. (b) HA fragments induce IFN $\beta$ protein in RAW 264.7 macrophages in a dose dependent fashion with peak induction at $6 \mathrm{~h}$ with a dose of $500 \mathrm{\mu g} / \mathrm{ml}$. (c,d) HA fragments induce IFN $\beta$ RNA and protein in peritoneal macrophage cell line in a time dependent fashion with peak induction mRNA at $3 \mathrm{~h}$ and protein at $6 \mathrm{~h}$ in macrophages; cells were stimulated with $200 \mathrm{\mu g} / \mathrm{ml}$ of HA fragments. (e) Thioglycollate elicited primary mouse macrophages from C57BL/6 WT mice were stimulated with HA fragments $(200 \mu \mathrm{g} / \mathrm{ml})$ for $6 \mathrm{~h}$ and IFNß protein secretion was measured by ELISA. These figures are representative of at least 3-4 identical experiments done in triplicate. ${ }^{\star} p \leq 0.05$ vs. unstimulated. 
stimulation [17]. Additionally, the ability of HA fragments to induce IFN $\beta$ was observed in primary peritoneal macrophages indicating that our results were not confined to cultured cell lines (Figure 1e). Thus, HA fragments can induce the induction of IFN $\beta$ RNA and protein in both macrophage cell lines and primary macrophages.

\section{Specific induction of IFN $\beta$ by HA fragments}

In the lung at rest, HA exists in a high molecular weight form that plays roles in maintaining tissue integrity and water homeostasis [7]. We have previously shown that upon tissue damage the HA is broken down into lower molecular weight fragments, and that only this form acts as an endogenous danger signal by activating the innate immune response [9]. To determine if hyaluronan induction of IFN $\beta$ is specific to HA fragments, macrophages were stimulated with HA fragments, high molecular weight HA, or other glycoasminoglycans in serum free RPMI for 3 hours. Total RNA was then isolated and analyzed by quantitative PCR. As predicted, HA fragments but not high molecular weight HA induced the production of IFN $\beta$ Figure 2). Furthermore, other glycosaminoglycans such as HA disaccharides, chrondroitan sulfate A (CSA), and heparin, failed to induce IFN $\beta$ mRNA expression (Figure 2).

\section{TLR4 but not TLR2 is required for HA fragment induction of IFN $\beta$}

We have previously demonstrated that HA fragments induce inflammatory cytokines via a TLR2-MyD88dependent pathway [9]. Others have implicated TLR4, or the combination of TLR2 and TLR4 in response to hyaluronan fragments of various sizes $[8,18]$. TLR4, TLR3, and TLR9 are well established as inducers of IFN $\beta$ expression. Although recently vaccinia has been reported to induce IFN $\beta$ via TLR2, in general TLR2 signaling pathways do not induce IFN $\beta$. [19-24]. In some models TLR2 agonists actually inhibit IFN $\beta$ production [25]. Thus, we wanted to determine which, if any, of the

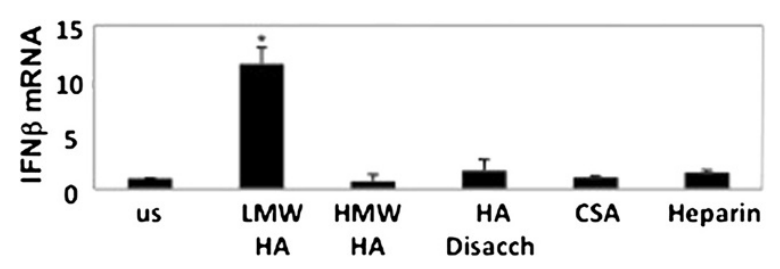

Figure 2 HA fragments induce IFN $\beta$ in a specific fashion. RAW 264.7 macrophages were stimulated with LMW HA fragments $(200 \mu \mathrm{g} / \mathrm{ml})$ for $3 \mathrm{~h}$, RNA extracted and Real-Time PCR performed for IFN $\beta$. HA fragments but not HMW HA, HA disaccharides, chondroitan sulfate $A$ (CSA) or heparin induce IFN $\beta$ mRNA. This figure is representative of at least 3 identical experiments done in triplicate. ${ }^{\star} p \leq 0.01$ vs. unstimulated.
TLR receptors was involved in mediating HA-induced IFN $\beta$ expression. Thiolglycollate-elicited primary macrophages were harvested from TLR2 null, TLR4 null, and wild type (WT) mice and stimulated in serum-free media with $200 \mathrm{ug} / \mathrm{mL}$ of LMW HA for 3 hours. RNA was extracted and analyzed by real time quantitative PCR. Both TLR2 null and WT macrophages responded briskly to HA fragments, with a marked and significant increase in IFN $\beta$ mRNA. However, the TLR4 null macrophages failed to produce IFN $\beta$ after LMW HA stimulation (Figure 3a). In contrast, LMW HA-induced MIP1 $\alpha$ production was reduced in macrophages from TLR2 null mice but robustly induced by macrophages lacking TLR4. In addition, macrophages from both TLR2 and TLR4 null mice demonstrated robust expression of IFN $\beta$ in response to poly (I:C), a TLR3 agonist.

TLR2 signaling thus proved to be necessary for the chemokine expression, but not the IFN $\beta$ expression induced by HA fragments. In contrast, TLR4 appeared responsible for HA-induced IFN $\beta$ expression but not chemokine expression. Thus, the ability of HA fragments to stimulate the C-C chemokine MIP1 $\alpha$ and IFN $\beta$ is by two distinct pathways: HA fragments induced chemokine expression via TLR2 while the same HA fragments induced type I interferon via TLR4.

To confirm the dependence of HA fragment-induced IFN $\beta$ on TLR4 we employed the pharmacologic inhibitor CLI-095 [26]. This molecule blocks TLR4 activation without inhibiting other MyD88-dependent signaling. Macrophages were pre-incubated with either CLI-095 or DMSO as a control for 30 minutes, stimulated with HA fragments or LPS for 3 hours, and then evaluated for IFN $\beta$ expression by RT PCR. Consistent with the observations in the TLR4 null macrophages, CLI-095 inhibited HA fragment induction of IFN $\beta$ mRNA by $80 \%$. As expected, CLI-095 also inhibited TLR4dependent LPS induction of IFN $\beta$ (Figure 3b). These data further support the finding that HA fragments induce IFN $\beta$ via a TLR4-dependent pathway.

\section{HA fragments induce IFN $\beta$ independent of MyD88 via TRIF}

The ability of HA fragments to induce IFN $\beta$ in a TLR4 dependent fashion was somewhat surprising. Previously, it has been shown that LMW HA fragments induced inflammatory gene expression via MyD88 $[8,9,18]$. However, IFN $\beta$ expression via TLR3 and TLR4, proceeds via MyD88-independent pathways $[19,21,22]$. Thus, we sought to determine whether HA fragment induction of IFN $\beta$ is MyD88 dependent. Thiolglycollate-elicited primary macrophages were harvested from MyD88 null and wild type mice, stimulated in serum-free media with $200 \mathrm{ug} / \mathrm{mL}$ of HA fragments, RNA was extracted and analyzed with real time PCR. HA fragments induced 

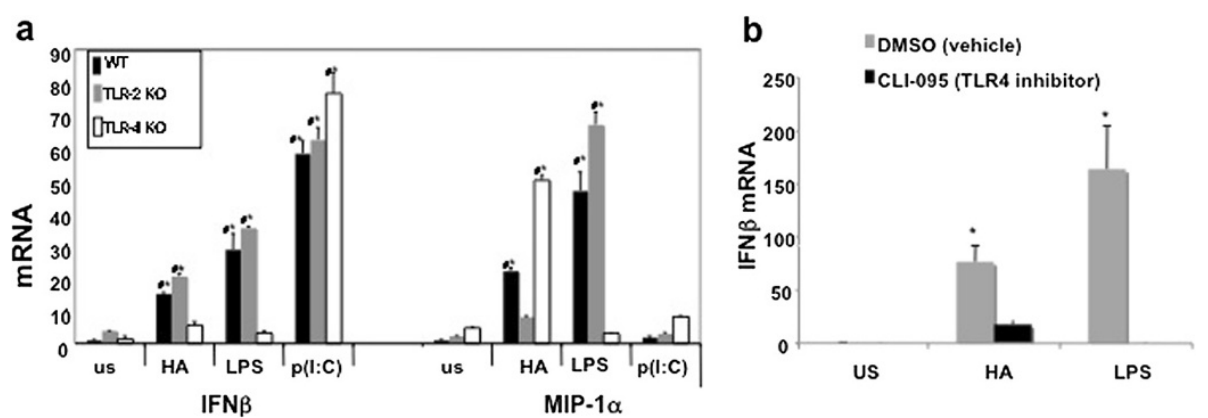

Figure 3 HA fragment induction of IFN $\beta$ is TLR-4 dependent. (a) Thioglycollate elicited peritoneal macrophages from C57BL/6 WT, TLR2 receptor null or TLR4 receptor null mice were stimulated with $200 \mathrm{ug} / \mathrm{mL}$ LMW HA fragments for 3 hours; cells were collected in Trizol, RNA extracted, and CDNA was analyzed with real-time PCR. HA fragment-induced MIP1a requires TLR2; HA induction of IFN $\beta$ was independent of TLR2 but required TLR4. Data demonstrate IFN $\beta$ induction compared to WT unstimulated levels; ${ }^{\star} p<0.05$ compared to WT unstimulated; $\#=p<0.05$ compared to genotype specific unstimulated). (b) Pharmacological inhibition of TLR4 significantly decreases HA fragment activation of IFN $\beta$. RAW 264.7 macrophages were prestimulated with $1 \mathrm{ug} / \mathrm{mL}$ CLI-095 for thirty minutes, prior to HA fragments (200 ug/ml) or LPS (100 ng/ml) for 3 hours. Cells were collected in Trizol, RNA extracted, and CDNA was analyzed with real-time PCR. Blocking the TLR4 receptor with CLI-095 significantly inhibited both HA fragment and LPS induction of IFN $\beta$. Values shown are mean fold induction over WT unstimulated; These figures are representative of at least 3-4 identical experiments done in triplicate ${ }^{\star} p<0.05$ unstimulated stimulated.

similar levels of IFN $\beta$ mRNA in both MyD88 null and WT macrophages (Figure 4a). In contrast, the production of the inflammatory cytokine MIP1 $\alpha$ was reduced in the MyD88 null mice (Figure 4a). These data demonstrate that HA-induced IFN $\beta$ proceeds via a MyD88-independent pathway, and thus identifies a novel signaling pathway responsible for HA fragment-induced inflammatory gene expression.

As IFN $\beta$ is known to be induced by TLR3, we wanted to insure that HA induction of IFN $\beta$ via TLR4 was not also utilizing TLR3 [3]. Therefore, thioglycollate-elicited primary macrophages were harvested from TLR3 null and WT mice, stimulated in serum free media with $200 \mathrm{ug} / \mathrm{mL}$ of HA fragments for 3 hours, and RNA was extracted and analyzed with real time PCR. HA fragments equally induced IFN $\beta$ mRNA in both WT and TLR3 null macrophages (Figure 4b). Thus, HA fragment-induced IFN $\beta$ is not dependent on TLR3.

Since HA did not require MyD88 for induction of IFN $\beta$ via TLR4, we hypothesized that HA fragment-induced IFN $\beta$ expression required the TIR-domain-containing adapter-inducing interferon- $\beta$ adaptor protein (TRIF). Thiolglycollate-elicited primary macrophages were harvested from TRIF null and WT mice, stimulated in serum free media with $200 \mathrm{ug} / \mathrm{mL}$ of HA for 3 hours, RNA was extracted and analyzed with real time PCR. HA fragment induction of IFN $\beta$ mRNA was markedly reduced in TRIF null macrophages (Figure 4c). In contrast, the production of inflammatory cytokine MIP1 $\alpha$ by HA fragments was not affected in the TRIF null macrophages. Thus, LMW HA induces IFN $\beta$ via a TLR4-TRIF-dependent pathway.

IFN $\beta$ is also known to be induced via a TLR-TBK1 pathway [3]. As the TLR3 receptor was not required in our model, we wanted to determine if TBK1 was part of the HA fragment-induced TLR4-TRIF induction of IFN $\beta$. Macrophages were stimulated with $200 \mathrm{ug} / \mathrm{mL}$ HA for 3 hours with and without the TBK1 inhibitor BX795; RNA was isolated and real time PCR performed. HA fragments and poly(I:C) induced significantly less IFN $\beta$ in the presence of the TBK1 inhibitor (Figure $4 \mathrm{~d}$ and e) but HA-induced MIP1 $\alpha$ was not significantly inhibited. Thus, HA induced IFN $\beta$ via a TLR4-TRIFTBK1 dependent pathway.

\section{HA fragments induce phosphorylation of IRF-3}

Interferon response Factor 3 (IRF-3) is central to the production of interferon beta via the TLR3 and TLR4 pathway, while IRF7 appears to be dominant in the TLR9 signaling that predominates in plasmacytoid dendritic cell [27]. To determine the role of IRF-3 in HA fragment induction of IFN $\beta$, we performed western analysis of HA-stimulated macrophages and interrogated extracts for members of the IRF family. MH-S alveolar macrophages were stimulated with LMW HA $(200 \mathrm{ug} / \mathrm{mL})$ for $0,30,60,90$, and 120 minutes; nuclear extracts were prepared, and analyzed by western blot with actin as a loading control. Only IRF-3 was phosphorylated after HA fragment stimulation, with peak phosphorylation after 90 minutes (Figure 5a).

To demonstrate the functional consequences of IRF-3 phosphorylation we evaluated the ability of $\mathrm{HA}$ to stimulate an IRF-3-dependent IFN $\beta$-promoter-driven luciferase reporter construct. Cells were transiently transfected with the reporter construct and stimulated with HA fragments for 18 hours prior to cell extract isolation and IFN $\beta$ gene activity was determined by luciferase production. Transfected cells stimulated with LMW 


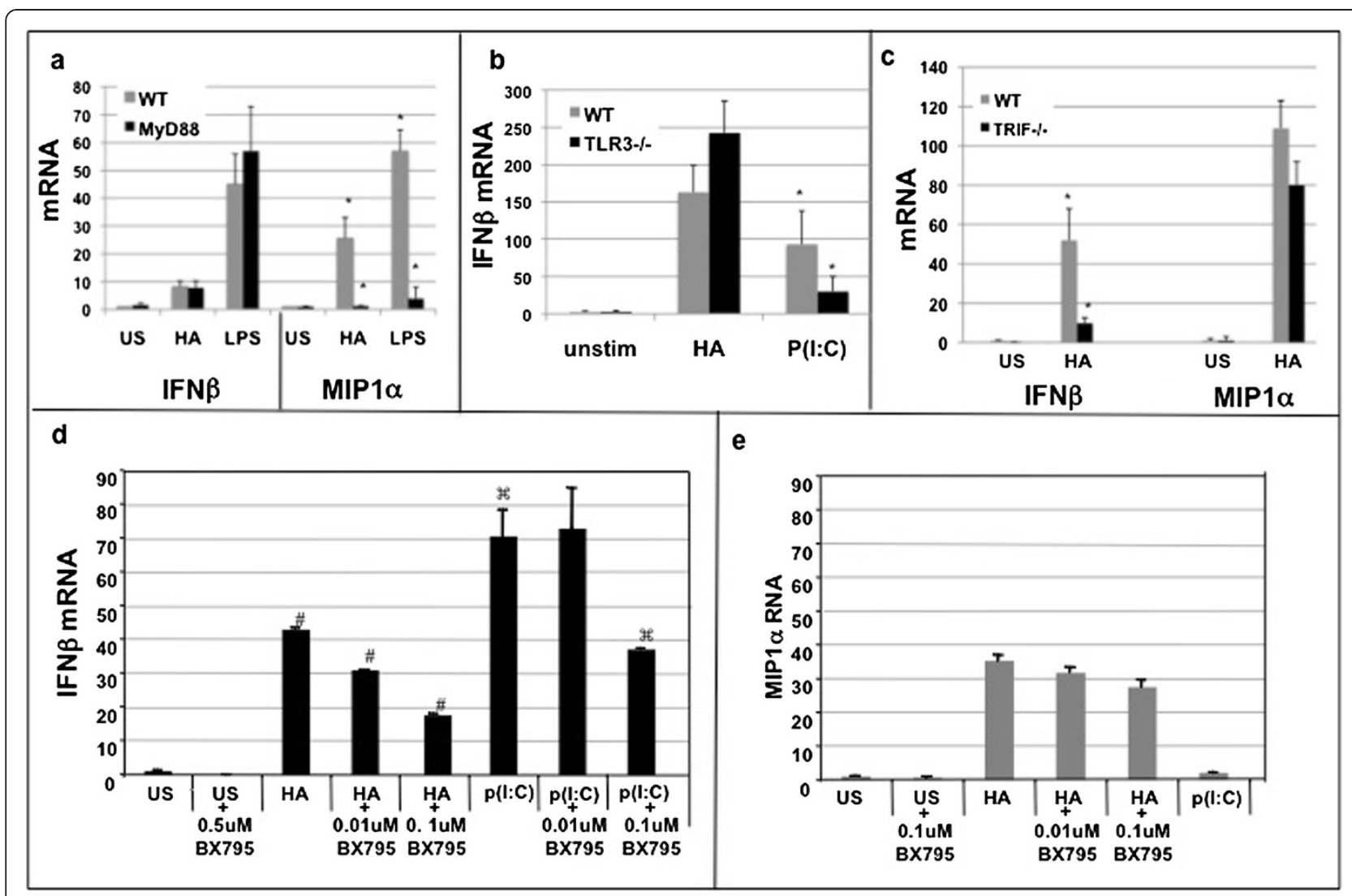

Figure 4 HA fragment induction of IFN $\beta$ is independent of MyD88, and TLR3 but dependent upon TRIF and TBK1. Thioglycollate elicited peritoneal macrophages from WT, MyD88 null, TLR3, TRIF null mice were stimulated with $200 \mathrm{ug} / \mathrm{mL}$ LMW HA fragments, LPS $10 \mathrm{ng} / \mathrm{ml}$ or p(l:C) $5 \mathrm{ug} / \mathrm{ml}$ for 3 hours; cells were collected in Trizol, RNA extracted, and cDNA was analyzed with real-time PCR (a) HA fragments require MyD88 to induce MIP1a but NOT IFNß. (b) TLR3 is not necessary for HA induced IFNß mRNA. (c) In the absence of TRIF, HA fragments induced significantly less IFN $\beta$. (d,e) RAW macrophages were stimulated with $200 \mathrm{ug} / \mathrm{mL}$ HA fragments for 3 hours +/- the TBK1 inhibitor BX795; RNA was isolated and Real-time PCR performed. HA fragments and $p(I: C)$ induced significantly less IFN $\beta$ in the presence of the TBK1 inhibitor but HA induced MIP1a was not significantly inhibited. Data reported as fold induction over WT unstimulated; data are mean of 3-7 experiments run in triplicate; ${ }^{*} p<0.05 \mathrm{HA}$ vs US; \# $\mathrm{p}<0.05$ HA vs HA + BX795; $\quad \mathrm{p}<0.05 \mathrm{p}(\mathrm{l}: \mathrm{C})$ vs $\mathrm{p}(\mathrm{l}: \mathrm{C})+\mathrm{BX795}$.

HA showed a dose-dependent increase in activation of the IFN $\beta$ gene (Figure $5 b$ ). These functional data support our model that HA fragments stimulate IFN $\beta$ expression in part through the activation of IRF-3.

\section{Discussion}

Hyaluronan (HA) is a glycosaminoglycan that plays an essential role in tissue integrity and water homeostasis [7]. During inflammation or tissue injury, the normally high molecular weight HA is broken down into low molecular weight fragments that induce inflammatory gene expression in macrophages, dendritic cells, $\mathrm{T}$ cells and epithelial cells [13-15,28]. HA fragments rapidly activate the innate immune response upon tissue damage even in the absence of or prior to the establishment of infection. Thus, we have proposed the HA fragments act as endogenous danger signal [9]. We now demonstrate that as an early danger signal HA fragments also induce Type
I interferons, which play a critical role in establishing anti-viral immune responses.

Furthermore, our studies identify an additional signaling pathway by which HA induces inflammatory gene expression. While it had previously been shown that HA fragments induced inflammatory gene expression is dependent upon MyD88 signaling, we now demonstrate a novel MyD88-independent TLR4-TRIF-TBK1 pathway for HA fragments induced IFN $\beta$ expression [9] (Figure 6). Thus our studies not only expand our understanding of the breadth of the inflammatory program induced by HA but also the intracellular signaling pathways employed by this endogenous inflammatory mediator. Our data further highlight the ability of this matrix component to modify the inflammatory milieu simultaneously via several distinct pathways.

Hyaluronan is produced by three isoforms of hyaluronan synthases and released from the plasma membrane into the extracellular space predominantly by fibroblasts [29]. 


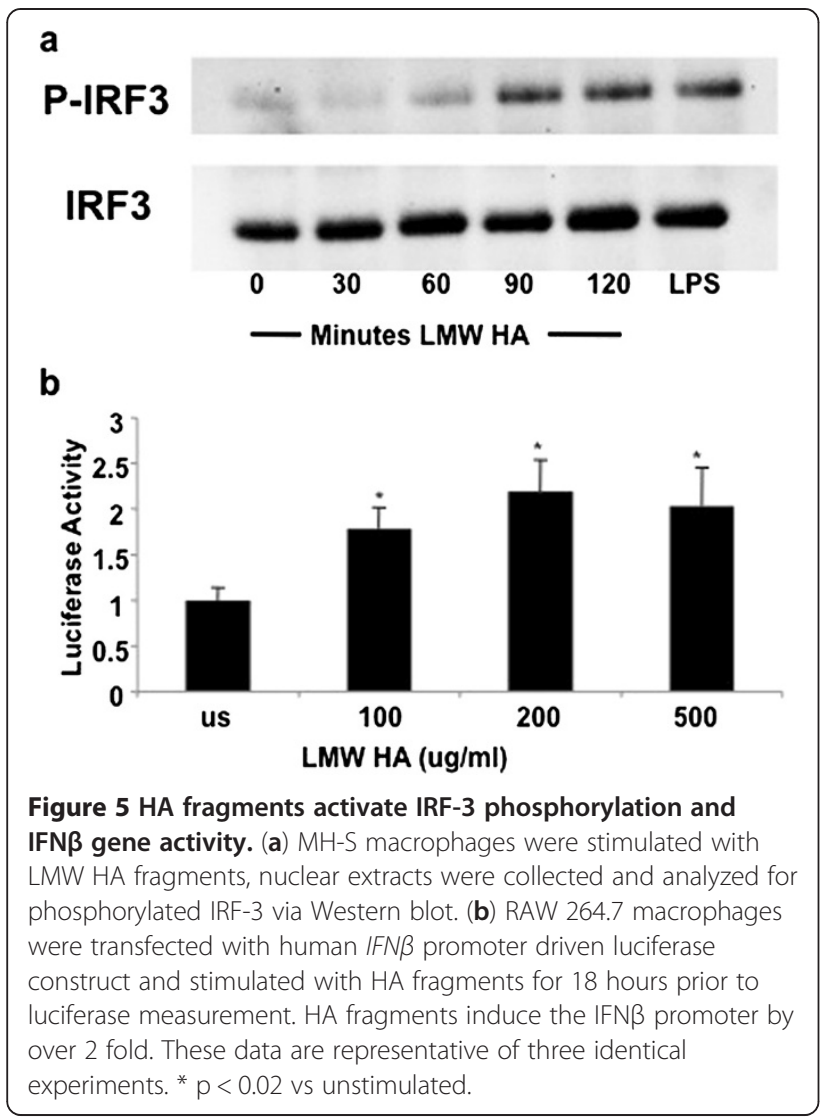

It abounds in synovial and vitreous fluids, and makes up $80 \%$ of the glycosaminoglycan in the lung $[7,10,30]$. In a healthy lung, HA exists predominantly in a high molecular weight form that is immunosuppressive by a variety of mechanisms; it enhances suppressive $\mathrm{T}$ regulatory cells,

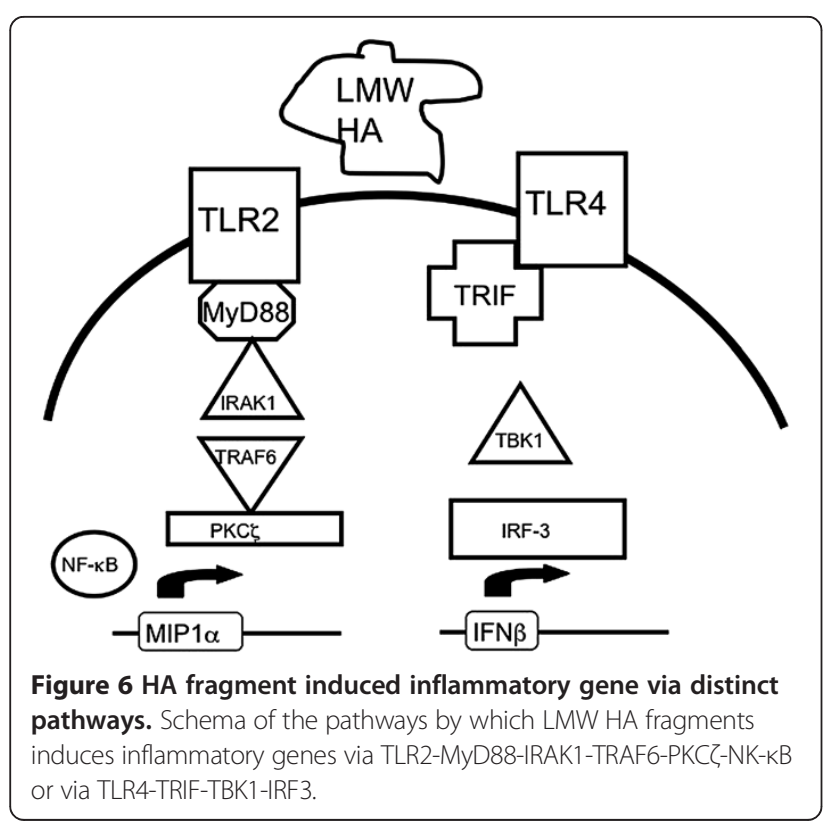

inhibits macrophage phagocytosis, and is important in maintaining distribution of plasma proteins $[7,10,30,31]$. However, low molecular weight fragments of HA produced both by breakdown of high molecular weight forms and by direct synthesis, have profound biological effects that oppose these pro-homeostatic effects $[8,9,11]$. The accumulation of HA fragments is itself a nonspecific response to lung injury.

Increased levels of HA fragments in the lung, at levels similar to the doses used in these experiments, are associated with a diverse set of injuries including ventilatorinduced lung injury, and bleomcyin and ozone exposure [32-36]. Mice lacking CD44, a major receptor for HA, have impaired clearance of HA fragments, and increased bleomcyin injury [11]. HA fragments instilled into the lung increases airway hyper-responsiveness in a CD44dependent manner [33]. HA fragments have been shown to mediate airway hyper-responsiveness seen with ozone exposure through both CD44 and TLR4 [33]. HA fragments promote production of inflammatory chemokines: MIP1 $\alpha$, MIP1 $\beta$, KC, RANTES, MCP- 1 and IP-10, as well as cytokines such as IL-8, IL-12 and TNF, via TLR2MyD88-IRAK-PK $\zeta$ binding [12-15]. In the bleomycin model of lung injury, mice lacking TLR2 are protected, while TLR2/TLR4 double null mice have increased mortality, suggesting that HA fragment-TLR2/TLR4 interactions have complex downstream effects $[8,37,38]$. The complete actions of HA fragments in the lung and other sites of tissue injury are still incompletely understood.

The generation of type I interferons is important not only locally but also systemically to condition and recruit immune cells to the site of infection [39]. The recognition of viral components and release of interferons is known to be mediated by TLR3, TLR7,TLR8 and TLR9 signaling as well as by more recently defined receptors such as RIG-I, MDA5 and DAI [39]. In addition, TLR4 signaling (for example by LPS) can lead to interferon production in a pathway dependent on STAT1 and the transcription factor IRF-3 [3]. TLR4 also uses an additional adaptor protein, TRAM, which seems to be unique to TLR4-induced interferon production $[3,19,27,40]$. In contrast, TLR2 ligands in general do not appear to phosphorylate STAT1 or lead to significant production of interferon beta in the majority of cases $[3,19,23,27,40]$. Here we demonstrate that LMW HA can increase production of IFN $\beta$. This effect is not via the ability of LMW HA to activate TLR2 (as has been previously described) but rather by TLR4 activation. Furthermore, unlike other LMW HA signaling, LMW HA-induced TLR4 activation depends on TRIF and not MyD88.

In a study on the effects of HA on neutrophils, Leu et al. observed that apoptosis of neutrophils is decreased in TLR4 null mice [41]. They demonstrated that was due to IFN $\beta$ mediated TRAIL-TRAILR interactions, as the 
addition of IFN $\beta$ led to an increase in TRAIL/TRAILR in inflammatory neutrophils. Administration of intratracheal HA fragments $(2000 \mathrm{ug} / \mathrm{ml})$ was found to result in an increase in IFN $\beta$ in whole lung neutrophils, an effect that was mitigated in the TLR4-/- mice. Our studies now provide a biochemical mechanism for these observations. Our data demonstrate that LMW HA directly induces IFN $\beta$ production and that this occurs via a newly defined TLR4TRIF-TBK1-IRF3 pathway. Thus, tissue damage causing fragmentation of matrix hyaluronan generating local high concentrations of HA fragment-induced IFN $\beta$ may prime the innate response for a potential viral infection (Figure 6), expanding the range of the 'danger signal' properties of LMW HA. The induction of IFN $\beta$ by HA, an endogenous danger signal, raises the possibility that the anti-viral effects of the interferons may be triggered early in injury, perhaps priming the immune system to launch a full anti-viral program.

Alternatively, the production of IFN $\beta$ may be intended to modify the pro-inflammatory effects of HA. Although the type I interferons are best known for their effects in viral infection, they also have the ability to inhibit inflammatory responses [6]. For example, in the eye, IFN $\beta$ appears to be important in suppressing inflammatory responses; IFN $\beta$ is produced in substantial amounts by retinal pigmented epithelial cells, and eliminates production of $\mathrm{T}$ cell chemoattractant CXCL9 in response to $\mathrm{TNF} \alpha / \mathrm{IFNg} / \mathrm{IL}-1 \beta$ [42]. Moreover, in a murine model, the increase in type I interferon ten days after influenza infection led to significantly decreased neutrophilic responses to subsequent bacterial pneumonia and increased mortality [43]. Therefore, HA induced activation of IFN $\beta$ via TLR4-TRIF-TBK1 may also act as a potential brake for innate inflammatory responses. Taken together, a model emerges whereby immediate tissue damage can lead to HA fragment-induced IFN $\beta$ that primes the innate response for a potential viral infection (Figure 6). Alternatively, persistent tissue damage leading to the accumulation of HA fragments may in fact serve to down regulate certain inflammatory responses. Thus this novel downstream effect of HA expands the role of this endogenous danger signal, and opens avenues for further investigation. In addition, the redundancy of inflammatory pathways triggered by LMW HA may also add to the robustness of an inflammatory response.

\section{Conclusions}

Low molecular weight fragments of the extracellular matrix component hyaluronan use many pathways to activate the immune system and modulate inflammation. We demonstrate a novel CD44 and MyD88 independent pathway for HA fragments to activate macrophage production of interferon- $\beta$ via TLR4-TRIF-TBK1-IRF3. Our data implicate HA fragment-induced interferons resulting from tissue damage as a novel potential endogenously derived warning system initiating an anti-viral response prior to the establishment of infection. Furthermore, this HAinduced gene expression is the result of a newly defined HA fragment downstream signaling pathway.

\section{Abbreviations \\ HA: Hyaluronan; IFN $\beta$ : Interferon $\beta$; LMW: Low molecular weight; HMW: High molecular weight.}

\section{Competing interests}

The authors declare that they have no competing interests.

\section{Authors' contributions}

KEB planned, performed, and analyzed most of the experiments and prepared the manuscript SLC, RSH, MJH, YC-L, and RWH assisted in planning and performing many of the experiments, JDP assisted in planning experiments and manuscript preparation, MRH planned experiments, analyzed data and prepared the manuscript. All authors read and approved the final manuscript.

\section{Acknowledgements}

Funding for this manuscript: NIH RO1 HL073855 (MRH), NIH RO1 HL0866332 (MRH)

\section{Author details}

'Department of Medicine, John Hopkins University School of Medicine, Baltimore, USA. ²Department of Oncology, Johns Hopkins University School of Medicine, Baltimore, USA.

Received: 30 July 2012 Accepted: 23 May 2013

Published: 30 May 2013

\section{References}

1. Pestka S, Langer JA, Zoon KC, Samuel CE: Interferons and their actions. Annu Rev Biochem 1987, 56:727-777.

2. Bogdan C, Mattner J, Schleicher U: The role of type I interferons in non-viral infections. Immunol Rev 2004, 202:33-48.

3. Chessler AD, Ferreira LR, Chang TH, Fitzgerald KA, Burleigh BA: A novel IFN regulatory factor 3-dependent pathway activated by trypanosomes triggers IFN-beta in macrophages and fibroblasts. J Immunol 2008, 181:7917-7924.

4. Khaitov MR, Laza-Stanca V, Edwards MR, Walton RP, Rohde G, Contoli M, Papi A, Stanciu LA, Kotenko SV, Johnston SL: Respiratory virus induction of alpha-, beta- and lambda-interferons in bronchial epithelial cells and peripheral blood mononuclear cells. Allergy 2009, 64:375-386.

5. Ashino S, Wakita D, Zhang Y, Chamoto K, Kitamura H, Nishimura T: CpGODN inhibits airway inflammation at effector phase through downregulation of antigen-specific Th2-cell migration into lung. Int Immunol 2008, 20:259-266.

6. Taniguchi T, Ogasawara K, Takaoka A, Tanaka N: IRF family of transcription factors as regulators of host defense. Annu Rev Immunol 2001, 19:623-655.

7. Laurent TC, Laurent UB, Fraser JR: The structure and function of hyaluronan: An overview. Immunol Cell Biol 1996, 74:A1-A7.

8. Jiang D, Liang J, Fan J, Yu S, Chen S, Luo Y, Prestwich GD, Mascarenhas MM, Garg HG, Quinn DA, et al: Regulation of lung injury and repair by Toll-like receptors and hyaluronan. Nat Med 2005, 11:1173-1179.

9. Scheibner KA, Lutz MA, Boodoo S, Fenton MJ, Powell JD, Horton MR: Hyaluronan fragments act as an endogenous danger signal by engaging TLR2. J Immunol 2006, 177:1272-1281.

10. Bollyky PL, Lord JD, Masewicz SA, Evanko SP, Buckner JH, Wight TN, Nepom GT: Cutting edge: high molecular weight hyaluronan promotes the suppressive effects of CD4 + CD25+ regulatory T cells. J Immunol 2007, 179:744-747.

11. Teder P, Vandivier RW, Jiang D, Liang J, Cohn L, Pure E, Henson PM, Noble PW: Resolution of lung inflammation by CD44. Science 2002, 296:155-158.

12. Hodge-Dufour J, Noble PW, Horton MR, Bao C, Wysoka M, Burdick MD, Strieter RM, Trinchieri G, Pure E: Induction of IL-12 and chemokines by hyaluronan requires adhesion-dependent priming of resident but not elicited macrophages. J Immunol 1997, 159:2492-2500. 
13. Horton MR, Olman MA, Bao C, White KE, Choi AM, Chin BY, Noble PW, Lowenstein CJ: Regulation of plasminogen activator inhibitor-1 and urokinase by hyaluronan fragments in mouse macrophages. Am J Physiol Lung Cell Mol Physiol 2000, 279:L707-L715.

14. Horton MR, Shapiro S, Bao C, Lowenstein CJ, Noble PW: Induction and regulation of macrophage metalloelastase by Hyaluronan fragments in mouse macrophages. J Immunol 1999, 162(7):4171-4176

15. McKee C, Penno M, Cowman M, Burdick M, Strieter R, Bao C, Noble P. Hyaluronan (HA) fragments induce chemokine gene expression in alveolar macrophages. The role of HA size and CD44. J Clin Invest 1996, 98:2403-2413.

16. Mbawuike I, Herscowitz $\mathrm{H}$ : MH-S, a murine alveolar macrophage cell line: morphological, cytochemical, and functional characteristics. J Leuk Biol 1989, 46:119-127.

17. Horton MR, Burdick MD, Strieter RM, Bao C, Noble PW: Regulation of hyaluronan-induced chemokine gene expression by IL-10 and IFNgamma in mouse macrophages. J Immunol 1998, 160:3023-3030.

18. Termeer C, Benedix F, Sleeman J, Fieber C, Voith U, Ahrens T, Miyake K, Freudenberg M, Galanos C, Simon JC: Oligosaccharides of Hyaluronan activate dendritic cells via toll-like receptor 4. J Exp Med 2002, 195:99-111.

19. Kato A, Ogasawara T, Homma T, Batchelor J, Imai S, Wakiguchi H, Saito H, Matsumoto K: CpG oligodeoxynucleotides directly induce CXCR3 chemokines in human B cells. Biochem Biophys Res Commun 2004, 320:1139-1147.

20. Katoh S, Zheng Z, Oritani K, Shimozato T, Kincade PW: Glycosylation of CD44 negatively regulates its recognition of hyaluronan. J Exp Med 1995, 182:419-429.

21. Stetson DB, Medzhitov R: Type I interferons in host defense. Immunity 2006, 25:373-381.

22. Toshchakov V, Jones BW, Perera PY, Thomas K, Cody MJ, Zhang S, Williams BR, Major J, Hamilton TA, Fenton MJ, Vogel SN: TLR4, but not TLR2, mediates IFN-beta-induced STAT1alpha/beta-dependent gene expression in macrophages. Nat Immunol 2002, 3:392-398.

23. Barbalat R, Lau L, Locksley RM, Barton GM: Toll-like receptor 2 on inflammatory monocytes induces type I interferon in response to viral but not bacterial ligands. Nat Immunol 2009, 10:1200-1207.

24. Martinez J, Huang X, Yang Y: Direct TLR2 signaling is critical for NK cell activation and function in response to vaccinia viral infection. PLOS Pathog 2010, 6:e1000811.

25. Simmons DP, Canaday DH, Liu Y, Li Q, Huang A, Boom WH, Harding CV: Mycobacterium tuberculosis and TLR2 agonists inhibit induction of type I IFN and class I MHC antigen cross processing by TLR9. J Immunol 2010, 185:2405-2415.

26. Zhu N, Yuan WJ, Zhou Y, Peng Y, Gu L, Wang L: The expression and role of Toll receptor 4 in renal tubular epithelial cells in hepatitis $B$ virus infection. Zhonghua Nei Ke Za Zhi 2011, 50:505-509.

27. Honda K, Yanai H, Negishi H, Asagiri M, Sato M, Mizutani T, Shimada N, Ohba Y, Takaoka A, Yoshida N, Taniguchi T: IRF-7 is the master regulator of type-I interferon-dependent immune responses. Nature 2005, 434:772-777.

28. Boodoo S, Spannhake EW, Powell JD, Horton MR: Differential regulation of hyaluronan-induced IL-8 and IP-10 in airway epithelial cells. Am J Physiol Lung Cell Mol Physiol 2006, 291:L479-L486.

29. Adamia S, Maxwell CA, Pilarski LM: Hyaluronan and hyaluronan synthases: potential therapeutic targets in cancer. Curr Drug Targets CardiovasC Haematol Disord 2005, 5:3-14.

30. Bollyky PL, Wu RP, Falk BA, Lord JD, Long SA, Preisinger A, Teng B, Holt GE, Standifer NE, Braun KR, et al: ECM components guide IL-10 producing regulatory T-cell (TR1) induction from effector memory T-cell precursors. Proc Natl Acad Sci USA 2011, 108:7938-7943.

31. Tamoto K, Nochi H, Tada M, Shimada S, Mori Y, Kataoka S, Suzuki Y, Nakamura T: High-molecular-weight hyaluronic acids inhibit chemotaxis and phagocytosis but not lysosomal enzyme release induced by receptor-mediated stimulations in guinea pig phagocytes. Microbiol Immunol 1994, 38:73-80.

32. Heise RL, Stober V, Cheluvaraju C, Hollingsworth JW, Garantziotis S: Mechanical stretch induces epithelial-mesenchymal transition in alveolar epithelia via hyaluronan activation of innate immunity. J Biol Chem 2011 , 286:17435-17444.

33. Garantziotis S, Li Z, Potts EN, Kimata K, Zhuo L, Morgan DL, Savani RC, Noble PW, Foster WM, Schwartz DA, Hollingsworth JW: Hyaluronan mediates ozone-induced airway hyperresponsiveness in mice. J Biol Chem 2009, 284:11309-11317.
34. Zhao H, Leu SW, Shi L, Dedaj R, Zhao G, Garg HG, Shen L, Lien E, Fitzgerald $K A$, Shiedlin $A$, et al: TLR4 is a negative regulator in noninfectious lung inflammation. J Immunol 2010, 184:5308-5314.

35. Andersen NF, Vogel U, Klausen TW, Gimsing P, Gregersen H, Abildgaard N, Vangsted AJ: Vascular endothelial growth factor (VEGF) gene polymorphisms may influence the efficacy of thalidomide in multiple myeloma. Int J Cancer 2011, 131(5):E636-42.

36. Savani RC, Hou G, Liu P, Wang C, Simons E, Grimm PC, Stern R, Greenberg $\mathrm{AH}$, DeLisser HM, Khalil N: A role for hyaluronan in macrophage accumulation and collagen deposition after bleomycin-induced lung injury. Am J Respir Cell Mol Biol 2000, 23:475-484.

37. Liu HZ, Yang HZ, Mi S, Cui B, Hua F, Hu ZW: Toll like receptor 2 mediates bleomycin-induced acute lung injury, inflammation and fibrosis in mice. Yao Xue Xue Bao 2010, 45:976-986.

38. Yang HZ, Cui B, Liu HZ, Chen ZR, Yan HM, Hua F, Hu ZW: Targeting TLR2 attenuates pulmonary inflammation and fibrosis by reversion of suppressive immune microenvironment. J Immunol 2009, 182:692-702.

39. Lopez $C B$, Hermesh $T$ : Systemic responses during local viral infections: type I IFNs sound the alarm. Curr Opin Immunol 2011, 23:495-499.

40. Krieg AM: CpG motifs in bacterial DNA and their immune effects. Annu Rev Immunol 2002, 20:709-760.

41. Leu SW, Shi L, Xu C, Zhao Y, Liu B, Li Y, Shiedlin A, Xiang C, Shen H, Quinn DA, et al: TLR4 through IFN-beta promotes low molecular mass hyaluronaninduced neutrophil apoptosis. J Immunol 2011, 186:556-562.

42. Maeyer E, Maeyer-Guignard JDE: Interferon-gamma. Curr Opin Immunol 1992, 4:321.

43. Shahangian A, Chow EK, Tian X, Kang JR, Ghaffari A, Liu SY, Belperio JA, Cheng G, Deng JC: Type I IFNs mediate development of postinfluenza bacterial pneumonia in mice. J Clin Invest 2009, 119:1910-1920.

doi:10.1186/1476-9255-10-23

Cite this article as: Black et al.: Hyaluronan fragments induce IFN $\beta$ via a novel TLR4-TRIF-TBK1-IRF3-dependent pathway. Journal of Inflammation $201310: 23$

\section{Submit your next manuscript to BioMed Central and take full advantage of:}

- Convenient online submission

- Thorough peer review

- No space constraints or color figure charges

- Immediate publication on acceptance

- Inclusion in PubMed, CAS, Scopus and Google Scholar

- Research which is freely available for redistribution 